\title{
Biocompatibility and Functionality of a Tissue-Engineered Living Corneal Stroma Transplanted in the Feline Eye
}

\author{
Marie Boulze Pankert, ${ }^{1,2}$ Benjamin Goyer, ${ }^{3}$ Fatma Zaguia, ${ }^{1}$ Myriam Bareille, ${ }^{1}$ \\ Marie-Claude Perron, ${ }^{1}$ Xinling Liu, ${ }^{1,4}$ J. Douglas Cameron, ${ }^{5}$ Stéphanie Proulx, ${ }^{3,6}$ \\ and Isabelle Brunette ${ }^{1,4}$
}

\begin{abstract}
${ }^{1}$ Maisonneuve-Rosemont Hospital Research Center, Montreal, Québec, Canada
${ }^{2}$ Département d'ophtalmologie, Université d'Aix-Marseille, Marseille, France

${ }^{3}$ Centre de recherche du CHU de Québec, Axe médecine régénératrice, Hôpital St-Sacrement, CUO-Recherche, and Centre de recherche en organogenèse expérimentale de l'Université Laval/LOEX, Québec City, Québec, Canada

${ }^{4}$ Department of Ophthalmology, University of Montreal, Montreal, Québec, Canada

${ }^{5}$ Ophthalmology and Visual Neurosciences and Laboratory Medicine and Pathology, University of Minnesota School of Medicine, Minneapolis, Minnesota, United States

${ }^{6}$ Département d'ophtalmologie et d'oto-rhino-laryngologie - chirurgie maxillo-faciale, Faculté de médecine, Université Laval, Québec City, Québec, Canada
\end{abstract}

Correspondence: Isabelle Brunette, Department of Ophthalmology, Maisonneuve-Rosemont Hospital, 5415 boulevard de L'Assomption, Montreal, QC H1T 2M4 Canada;

i.brunett@videotron.ca.

Submitted: May 2, 2014

Accepted: September 17, 2014

Citation: Boulze Pankert M, Goyer B, Zaguia F, et al. Biocompatibility and functionality of a tissue-engineered living corneal stroma transplanted in the feline eye. Invest Ophthalmol Vis Sci. 2014;55:6908-6920. DOI:

10.1167/iovs.14-14720
Purpose. Corneal tissue shortage has become a major concern worldwide, which has motivated the search for alternative solutions to eye bank human eyes for corneal transplantation. Minimally invasive lamellar transplantation and tissue engineering may offer new opportunities for the rehabilitation of diseased corneas. The aim of this study was to evaluate the biocompatibility and functionality of stromal lamellar grafts tissue-engineered (TE) in vitro and transplanted in vivo in the cornea of a feline model.

Methods. The corneal stromas were engineered in culture from corneal stromal cells using the self-assembly approach, without the addition of exogenous material or scaffold. Eight healthy animals underwent two intrastromal grafts in one eye and the contralateral eye was used as a control. Animals were followed with slit-lamp ophthalmic examination, corneal esthesiometry and optical coherent tomography. Confocal microscopy, immunofluorescence, histology, and transmission electron microscopy (TEM) were performed at 4 months.

REsults. Four months after transplantation, the TE-stromal grafts were transparent, functional, and well tolerated by the eye. All grafts remained avascular, with no signs of immune rejection, despite a short course of low-dose topical steroids. Corneal sensitivity returned to preoperative level and reinnervation of the grafts was confirmed by confocal microscopy and immunofluorescence. Histology and TEM of the TE-grafts showed a lamellar stromal structure with regular collagen fibril arrangement.

Concuusions. These results open the way to an entirely new therapeutic modality. Intracorneal filling using a biocompatible, transparent, and malleable TE-stroma could be the basis for multiple types of novel therapeutic options in corneal interventional surgery.

Keywords: tissue engineering, corneal transplantation, corneal stroma, corneal substitute, reinnervation, cell culture

\begin{abstract}
Corneal tissue shortage has become a major concern worldwide, the supply of donor tissue clearly not meeting the increasing demand. ${ }^{1}$ Alternative solutions to eye bank human eyes for corneal transplantation are needed, corneal blindness representing the fourth most important cause of visual impairment in the world, after cataract, glaucoma and agerelated macular degeneration.,3 Irreversible corneal damage has traditionally been treated with full thickness corneal transplantation using eye bank corneas. These standards, however, may have to change. The growing experience developed in different parts of the world with lamellar corneal transplantation and with tissue engineering may open the way to new solutions. Lamellar transplantation is based on the selective replacement of the diseased corneal layers. It may relieve some of the pressure on eye banks by reducing the severity of the exclusion criteria,
\end{abstract}

which could be limited to specific corneal layers. Tissue engineering also offers a new and promising opportunity to overcome tissue shortage, based on the production of transplantable corneal tissue layers, such as epithelium, ${ }^{4,5}$ endothelium, ${ }^{6-8}$ or stroma. We herein focused on the concept of lamellar transplantation of a tissue-engineered (TE) corneal stroma.

Several alternatives to native tissue have been proposed for corneal stromal replacement. Synthetic, rigid, and inert keratoprostheses, with transparent optical components usually made of PMMA or poly[2-hydroxyethyl methacrylate], have been implanted for several decades in human subjects. Although these prostheses can restore sight, their prognosis is overshadowed by a significant risk for infection, dehiscence, and extrusion, due to the lack of integration of the nonbiological material within the host's corneal tissue. ${ }^{9,10}$ 
A variety of synthetic and acellular biomaterials aimed at replacing the corneal stroma have been tested experimentally, with mitigated success. Polyvinyl alcohol hydrogel ${ }^{11}$ and expanded polytetrafluoroethylene implants, ${ }^{12}$ for instance, offer interesting optical properties and low immunogenicity, but are compromised by low cell affinity or biocompatibility. Biocompatibility is improved with polyethylene glycol-diacrylate $\mathrm{e}^{13}$ or type I collagen, chitosan, and glycosaminoglycans ${ }^{14}$ implants; however, with variable degrees of transparency and tendency for biodegradation. In an attempt to improve in vivo stability, corneal stromal cells have been introduced on the surface or within various substrates, such as synthetic polymers ${ }^{15}$ and gelatin hydrogel. ${ }^{16}$ These results have highlighted the benefits of generating cytocompatible biomaterials in order to improve biointegration of the stromal implant.

An intermediate option, consisting of a cell-free scaffold permeable to the host's corneal cells and nerves has been proposed by Griffith's group. This stromal substitute made of cross-linked recombinant human collagen was implanted in 10 human subjects, ${ }^{17}$ which represents an advance in the field of stromal replacement.

The new concept proposed herein combines both alternatives of tissue engineering and lamellar transplantation. The stromal tissue described herein is different and complementary to that of an acellular biosynthetic implant or scaffold, as it is entirely engineered from stromal cells (keratocytes) prior to transplantation. Keratocytes can be isolated and easily expanded in vitro. When cultured in the presence of serum, they acquire a fibroblastic phenotype and are called "corneal fibroblasts." 18 The self-assembly approach is based on the natural capacity of corneal stromal fibroblasts to secrete and assemble their own extracellular matrix without the addition of exogenous biomaterial. The stromal sheets generated are then stacked to form a thicker stromal substitute. ${ }^{19}$ This approach is now used to engineer skin transplants for the treatment of severe burns ${ }^{20}$ and lower-extremity chronic skin ulcers. ${ }^{21}$ It is also under investigation for the engineering of blood vessels ${ }^{22}$ and adipose tissue. ${ }^{23}$ The corneal stromal tissue produced with this technique opens the door to an entirely new generation of therapeutic options for the rehabilitation of a wide range of diseased corneas.

The aim of this study was to evaluate the biocompatibility and functionality of this corneal stromal tissue engineered in vitro using the self-assembly technique and transplanted in vivo in the cornea of a feline model.

\section{Materials AND Methods}

All experiments were conducted in accordance with the ARVO statement for the Use of Animals in Ophthalmic and Vision Research for the duration of all the experiments. The research protocol was approved by the Maisonneuve-Rosemont Hospital Animal Protection committee.

\section{Tissue Engineering of the Corneal Stroma}

Isolation and Culture of Human and Feline Corneal Cells. The human corneas of a 26-day-old human donor unsuitable for transplantation were obtained from our local eye bank (Banque d'Yeux du Centre Universitaire d'Ophtalmologie, Québec, QC, Canada). Keratocytes were isolated after dispase digestion and removal of the epithelium and endothelium. They were cultured in fibroblast culture medium consisting of DMEM supplemented with $10 \%$ fetal calf serum (Hyclone, Logan, UT, USA), $25 \mu \mathrm{g} / \mathrm{mL}$ gentamycin sulphate (Schering, Pointe Claire, QC, Canada), and $100 \mathrm{IU} / \mathrm{mL}$ penicillin G (Sigma, Oakville, ON, Canada). ${ }^{24-26}$ Feline keratocytes were isolated ( $n=1$ pair of eyes) and cultured using the same protocol as for human cells.
Tissue Engineering of Human and Feline Stromas Using the Self-Assembly Approach. Corneal fibroblasts were seeded at a density of 100 cells $/ \mathrm{mm}^{2}$ and cultured in fibroblast growth medium supplemented with $50 \mu \mathrm{g} / \mathrm{mL}$ ascorbic acid (Sigma) for 28 (feline cells) or 35 (human cells) days. Fibroblasts secreted their own extracellular matrix and generated thick sheets, six of which were stacked to produce a thick corneal stroma. ${ }^{26}$

In Vitro Assessment of Stromal Compatibility With Neurite Outgrowth. Compatibility with reinnervation was assessed in vitro. Sensory neurons (given by François Berthod) were extracted from the dorsal root ganglion (DRG) of mice embryos (E12.5, CD-1 mice; Charles River Laboratories, Lasalle, QC, Canada), ${ }^{27}$ washed, and trypsinized. We seeded 2000 DRG/ $\mathrm{mm}^{2}$ on the tissue-engineered corneal stromas and cultured in growth medium containing $10 \mathrm{ng} / \mathrm{mL}$ nerve growth factor (Feldan, Québec, QC, Canada) for 14 and 21 days. ${ }^{28}$ Tissues were then processed for immunofluorescent labeling. None of the tissues seeded with DRG were transplanted in vivo.

\section{Population}

Eight healthy domestic felines aged between 10.3 and 19.4 months (15.4 \pm 3.5 months) and weighing between 2.7 and $4.7 \mathrm{~kg}(3.7 \pm 0.9 \mathrm{~kg})$ were used for this study. One eye per animal was randomly assigned to transplantation of two TEstromal grafts and the contralateral eye was used as a control. Four animals received grafts engineered from feline cells (allografts) and four animals received grafts engineered from human cells (xenografts).

\section{Surgical Protocol}

Surgery was performed under general anesthesia. ${ }^{29}$ Two limbal incisions 4-mm long and 300- $\mu \mathrm{m}$ deep were made poles apart in the superior nasal and inferior temporal quadrants, using a micrometric diamond knife (Meyco; Anton Meyer \& Co., Ltd., Biel, Switzerland) and a $7-\mathrm{mm}$ long intrastromal lamellar dissection was made toward the center of the cornea using a crescent knife (Alcon Canada, Inc., Mississauga, Canada). Two TE-stromal grafts were cut (4-mm Acupunch; Acuderm, Inc., Fort Lauderdale, FL, USA) and a graft was inserted in each intrastromal pocket, leaving a 2-mm clear zone between the graft and the limbus (Fig. 1). In the mate control eye, a similar lamellar dissection was made in the inferior temporal quadrant without tissue insertion. No sutures were applied to any of the grafts and all limbal wounds were closed (CU-1 10-0 nylon; Alcon Surgical, Fort Worth, TX, USA).

\section{Postoperative Medication}

At the end of the surgery, animals received subconjunctival injections of dexamethasone $(1.2 \mathrm{mg}$ in $0.3 \mathrm{~mL})$, tobramycin (10 $\mathrm{mg}$ in $0.25 \mathrm{~mL}$ ), and cefazolin $(55 \mathrm{mg}$ in $0.25 \mathrm{~mL}$ ). Sutures were removed on day 7 . During the postoperative period, tobramycin $0.3 \%$ and dexamethasone $0.1 \%$ (Tobradex; Alcon Canada, Inc.) and diclofenac $0.1 \%$ drops (Voltaren Ophthalmic; Novartis Pharmaceuticals Corp., East Hanover, NJ, USA) were applied three times a day for the first week and tapered over 1 month. No systemic antibiotics or steroids were given. Prophylactic famciclovir (Famvir $125 \mathrm{mg} /$ day per OS; Novartis Pharmaceutical Corp.) was given during the entire study period.

\section{Standard Follow-up}

Animals were examined before surgery, daily from postoperative days 1 to 4 , on days $7,8,10,15,18,22,25$, and 30 , and once a 
Grafted Eye (OD)

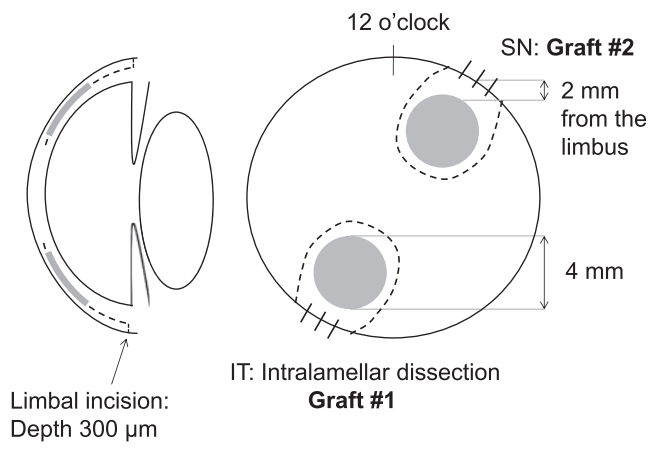

Control Eye (OS)

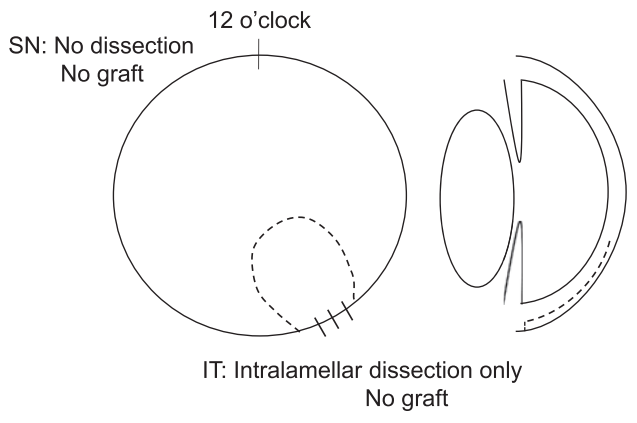

Figure 1. Surgical technique. Two 300- $\mu \mathrm{m}$ deep limbal incisions were made poles apart in the superior nasal (SN) and inferior temporal (IT) quadrants and an intrastromal lamellar dissection was made. A graft was inserted in each of these stromal pockets, leaving a 2-mm clear zone between the graft and the limbus. In the mate control eye, a similar lamellar dissection was made in the IT quadrant without tissue insertion. No sutures were applied to any of the grafts and all limbal wounds were closed.

week for the last 3 months. Each ophthalmic examination included slit-lamp photography (Haag-Streit, Bern, Switzerland); intraocular pressure measurement (Perkins handheld Tonometer Mk2; Haag-Streit, Edinburgh, UK); and central and midperipheral corneal pachymetry (ultrasound pachymeter SP 3000; Tomey, Nagoya, Japan). Two independent trained observers made all corneal examinations. Eyes were checked for graft clarity, signs of infection, inflammation, rejection, and neovascularization. Graft transparency was quantified according to a subjective 0 to +4 scale $^{30}$ (4+: clear graft allowing full visualization of iris details; $3+$ : slight opacity with iris/lens details easily visible; $2+$ : mild opacity, iris/lens still visible; $1+$ : moderate opacity with no iris/ lens details; and 0: opaque cornea). The presence of cells and flare in the anterior chamber was used to quantify inflammation according to a 0 to +4 scale. ${ }^{31}$ Corneal neovascularization was described in terms of superficial or deep, length, number of clock hours of limbal involvement, and flow rate (0: ghost vessel; +1 : low flow; +2 : high flow).

Corneal Sensitivity. Corneal sensitivity was measured using an esthesiometer (Cochet-Bonnet, 12/100 mm nylon thread; Luneau, Chartres, France). ${ }^{32,33}$ On an awake and quiet animal, the nylon monofilament was applied perpendicularly to the corneal surface and shortened by $0.5-\mathrm{cm}$ steps, from 6.0 $\mathrm{cm}$ (soft) to $0.5 \mathrm{~cm}$ (rigid). The longest filament length generating a blink reflex in more than half of five applications was recorded as the corneal sensitivity threshold. Measurements were taken centrally and in the four zones of interest.

Optical Coherence Tomography (OCT). Real-time OCT (Thorlabs, Inc., Newton, NJ, USA) was used to obtain in vivo noncontact, two-dimensional, cross-sectional images with resolution in the order of $4.4 \mu \mathrm{m}$. Corneal and graft thicknesses and graft depth were measured using ImageJ software (http:// imagej.nih.gov/ij/; provided in the public domain by the National Institutes of Health [NIH], Bethesda, MD, USA). ${ }^{34}$ The central, superior nasal, and inferior temporal zones of both corneas were studied. We performed OCT on days 3, 15, 30, 44 , and months 2, 3, and 4 after surgery. Six cross-sectional images (four horizontal and two vertical) were acquired for each zone of interest.

Specular Microscopy. Noncontact specular microscopy (Konan Medical, Inc., Nishinomiya, Hyogo, Japan) was performed before and 4 months after surgery to assess integrity of the corneal endothelium. This posterior monolayer of cells is responsible for actively dehydrating the cornea in order to maintain its transparency. ${ }^{35} \mathrm{~A}$ minimum of 100 cells per cornea were counted (KSS-409SP software, version 2.10, Cellchek XL; Konan Medical, Inc.).

\section{Postmortem Assessment}

Animals were euthanized on day 114 (pentobarbital sodium 3 $\mathrm{mL} / 2.5-5 \mathrm{~kg}$ intravenously). Grafted and control eyes were enucleated and examined. Wide angle OCT (Visante 1000; Carl Zeiss Meditec, Dublin, CA, USA) was performed to document the full corneal width from limbus to limbus.

Confocal Microscopy. Confocal microscopy (Rostock cornea module of Heidelberg Retina Tomograph II: RCM/HRT II; Heidelberg Engineering GmbH, Heidelberg, Germany) was performed on all eyes. Images $(400 \times 400 \mu \mathrm{m} ; 384 \times 384$ pixels) were obtained with a transversal optical resolution of 2 $\mu \mathrm{m}$, an axial optical resolution of $4 \mu \mathrm{m}$ and an acquisition time of 0.024 seconds. Semiautomated sequences of 30 images with incremental steps of $2 \mu \mathrm{m}$ were obtained from epithelium to endothelium, in the central, superior nasal, and inferior temporal zones of all corneas.

Nerve fiber analyses were focused on the subbasal nerve plexus (just anterior to Bowman's layer; $n=6$ consecutive images), the subepithelial nerve plexus (just posterior to Bowman's layer; $n=2$ consecutive images) and the TE-stromal grafts $(n=3$ consecutive images for each anterior, middle, and posterior third). Each nerve was only counted once. All analyses were repeated at corresponding depth in the control eye. The nerve tracing and analysis software (NeuronJ; Biomedical Imaging Group, Lausanne, Switzerland and Rotterdam, The Netherlands) was used in combination with the Image J software. ${ }^{34,36} \mathrm{~A}$ single observer masked for animal's identity, type of graft and clinical results made the analyses.

Five previously validated parameters were studied ${ }^{33,37-39}$ :

1. Nerve count, representing the total number of nerves observed within a $400 \times 400 \mu \mathrm{m}$ frame (expressed in number $\left./ \mathrm{mm}^{2}\right)$;

2. Density $\left(\mu \mathrm{m} / \mathrm{mm}^{2}\right)$, defined as the cumulative length of all nerves visible within a frame;

3. Length $(\mu \mathrm{m})$, defined as the average length of nerves within a frame;

4. Width $(\mu \mathrm{m})$, defined as the average width of nerves within a frame; and

5. Branching, which was described as present or absent.

Histology, Electron Microscopy, and Indirect Immunofluorescence. Histology, electron microscopy, and indirect immunofluorescence analyses were performed on the preoperative TE-stromas, on the grafts, as well as on the operated and unoperated native controls. One quarter of each cornea was fixed in $10 \%$ neutral buffered formalin and paraffin embedded 

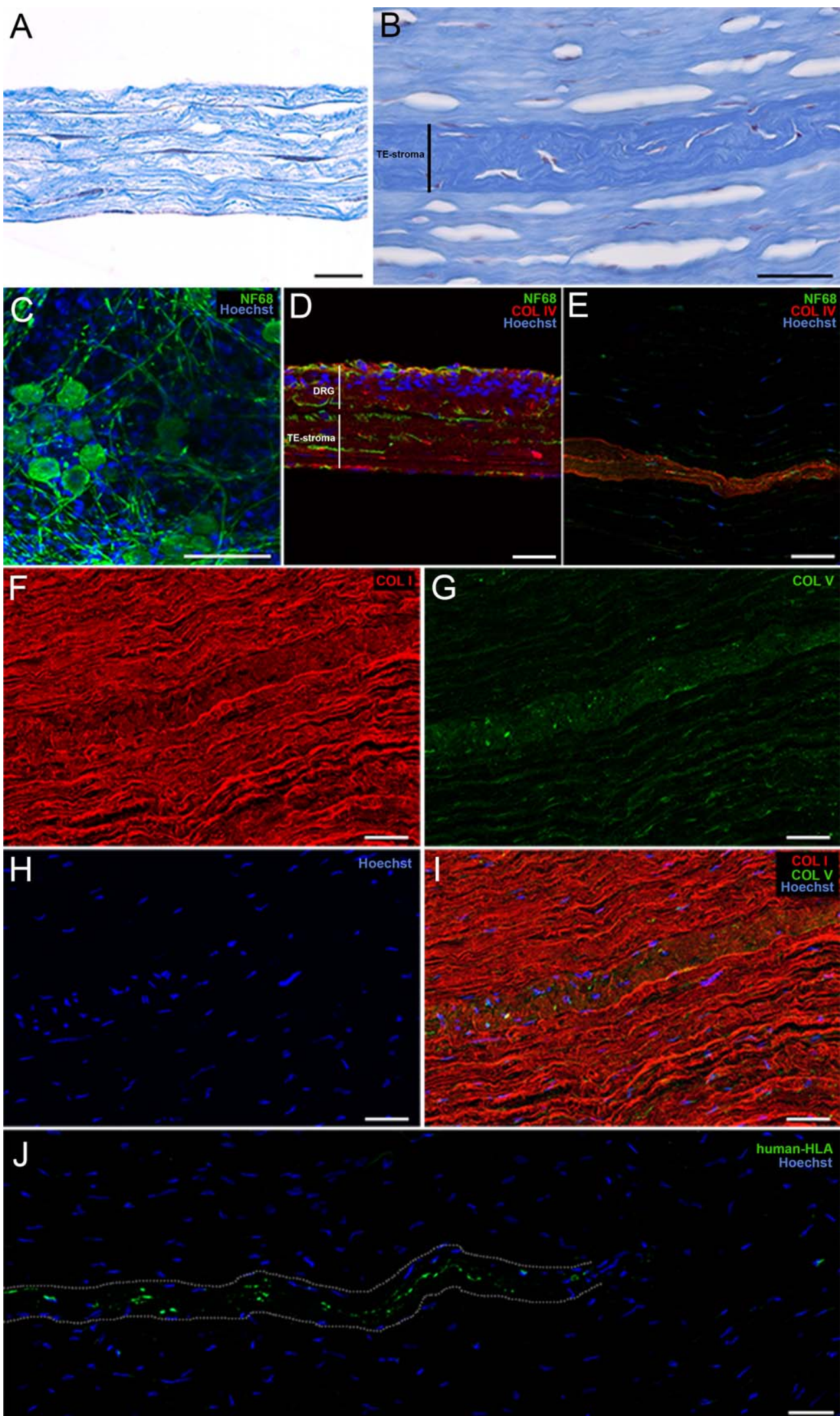

Figure 2. Histology and immunofluorescent staining of the TE-stromas. (A, B) Histology cross-sections (Masson trichrome staining). (A) Tissueengineered stroma in culture prior to transplantation showing fibroblasts imbedded between six sheets of extracellular matrix (Masson trichrome stains collagen in blue and cells in purple). $N=9$ TE-stromas, $n=4$ photographed sections per stroma. A representative photograph was chosen for the figure. (B) Tissue-engineered stromal graft 4 months after implantation in the feline cornea. $(N=8$ grafted corneas +8 control corneas, $n=3$ full thickness corneal sections per grafted or control cornea. A representative picture was chosen for the figure. (C, D) Pretest in culture: 
immunofluorescent staining of a subgroup of TE-stromas seeded with DRGs. None of the TE-stromas seeded with DRGs were transplanted in vivo. (C) En face view showing neurite outgrowth from the DRG cell bodies (NF68; green). Representative picture of four TE-stromas. (D) Cross-sectional view showing detection of the 68-kDa neurofilament (NF68; green) across the entire tissue thickness. We visualized the TE-stroma using an antibody directed specifically toward human type IV collagen (Coll IV, red). Cell nuclei were counterstained with Hoechst (blue). Representative picture of three TE-stromas. (E) Immunofluorescent staining of the TE-stromal graft 4 months after transplantation (NF68; green) and type IV collagen (red). Cell nuclei were counterstained with Hoechst (blue). (F-I) Immunofluorescent staining of the TE-stromal grafts 4 months after transplantation. (F) Type I collagen (red). (G) Type V collagen (green). (H) Hoechst staining (blue). (I) Merge of (F-H) $N=8$ grafted corneas. A representative region was chosen for the figure. (J) Human-HLA-ABC staining of a human TE-stroma transplanted in the feline eye, 4 months after transplantation. The dotted lines delineate the grafted TE-stroma. $N=3$ grafted corneas. A representative region was chosen for the figure. Scale bars: $20 \mu \mathrm{m}(\mathbf{A}) ; 50 \mu \mathrm{M}$ (B-J).

for light microscopy. A second quarter was fixed in $2.5 \%$ glutaraldehyde and prepared for transmission electron microscopy (TEM, Hitachi H-7500; Tokyo, Japan) as previously described. ${ }^{30}$ We used TEM images $(\times 100,000$ and $\times 200,000)$ to analyze distribution, diameter, and spacing of the stromal collagen fibrils. Forty collagen adjacent fibrils were randomly selected and measured in each sample. The ImageJ software was used. ${ }^{34}$

One half of each cornea was frozen in optimal cutting temperature solution (Somagen, Edmonton, AB, Canada) for immunodetection. ${ }^{7}$ We fixed $20-\mu \mathrm{m}$ cryosections 10 minutes at $-20^{\circ} \mathrm{C}$ using acetone $(90 \%$; EMD Serono Canada, Inc., Mississauga, ON, Canada) for all of the immunostainings except for anti-HLA, which were fixed 10 minutes at room temperature in 16\% paraformaldehyde (Electron Microscopy Sciences, Hatfield, PA, USA) then permeabilized 30 minutes in 0.2\% Tween-20 (Millipore Corp., Toronto, ON, Canada). Primary antibodies consisted of a chicken antineurofilament $68 \mathrm{KDa}$ (NF68; Millipore Corp.), a mouse anti-collagen I (Calbiochem; VWR International, Mississauga, ON, Canada); a rabbit anti-collagen IV human (Millipore Corp.); a rabbit anticollagen V (Cedarlane; Hornby, ON, Canada); and a mouse antihuman HLA-ABC (Millipore Corp.). Goat anti-chicken conjugated with AlexaFluor 488, donkey anti-mouse conjugated with AlexaFluor 488 or 594 and goat anti-rabbit conjugated with AlexaFluor 594 or 488 (all from Invitrogen Life Technologies, Burlington, ON, Canada) were used as secondary antibodies. Cell nuclei were counterstained with Hoechst reagent 33258. Fluorescence was observed using a confocal microscope (LSM700, Carl Zeiss Canada, Ltd., Toronto, ON, Canada). One transversal $0.36-\mu \mathrm{m}$ image, taken in the middle of the TEstroma, was used for the observation of NF68. Images (319.49 $\times 319.49 \mu \mathrm{m} ; 2048 \times 2048$ pixels) were obtained with a $z$-stack of $0.36 \mu \mathrm{m}$. Only one stack, taken in the middle of the TEstroma, was used for the observation of NF68.

\section{Statistical Analysis}

The mean \pm SD was used to describe continuous variables. Statistical comparisons between groups were performed using Student's $t$-test derived from a mixed model ANOVA. An unstructured covariance structure was used and the assumption of normality of the residuals was assessed. The mixed model was used to account for the correlation among multiple measures of an outcome on the same subject at different time points and/or different corneal zones.

\section{Results}

\section{In Vitro Characterization of the Engineered Stromal tissue}

Figures 2A through 2J illustrate the histological progression of the TE-stromas from culture to the eye. Figure $2 \mathrm{~A}$ shows the in vitro corneal stroma with six sheets of extracellular matrix. The mean thicknesses $( \pm \mathrm{SD})$ of the engineered stromas in culture was $61 \pm 15 \mu \mathrm{m}(N=9, n=27 ; 38-100 \mu \mathrm{m})$. Before transplantation, compatibility with axonal outgrowth was assessed by seeding and culturing the TE-stromas with sensory DRG. The sensory neurons seeded on top of the TE-stromas yielded axonal outgrowth on the surface, as well as within the deeper layers of the TE-stromas (Figs. 2C, 2D).

\section{In Vivo Assessment}

Graft Transparency. The 16 intrastromal grafts of the TEstroma laid at an average corneal depth of $272 \pm 50 \mu \mathrm{m}(182-$ $417 \mu \mathrm{m})$. Once transferred to their natural environment, the grafts rapidly cleared out. The average graft transparency score improved rapidly to $3.3 \pm 0.4$ on the first postoperative day and $3.9 \pm 0.2$ on day 37 , after which all grafts remained clear, allowing full visualization of the fine iris details with the same precision as for native corneas (Figs. 3A, 3B). These grafts were so clear that confirmation of their presence necessitated bright tangential illumination, as shown in Figure 3A (second row).

Intraocular Inflammation and Pressure. There were no signs of inflammation in any of the eyes prior to surgery. The minimal intraocular inflammation observed in the anterior chamber of all eyes (grafted and controls) on day 1 entirely resolved within a few days (Figs. 3C, 3D). All corneas remained avascular (a condition essential to preserve transparency) and no signs of rejection, such as graft edema, stromal infiltration or keratic precipitates, were seen at any time in any of the grafted eyes. Beside a small and transient rise early after surgery, intraocular pressure remained unaffected by surgery (Fig. 3E).

Endothelial Cell Density and Graft Thickness. Endothelial cell counts remained unchanged (preop grafted eyes: $2521 \pm 197$, postop grafted eyes: $2470 \pm 139$ cells $/ \mathrm{mm}^{2}, P=$ 0.182; preop control eyes: $2490 \pm 181$, postop control eyes: $2493 \pm 150, P=0.928)$ and endothelial function unaffected, as corroborated by the rapid resorption of graft edema. The average graft thickness decreased from $44.5 \pm 7.8 \mu \mathrm{m}$ on day 3 to $31.2 \pm 4.9$ on day $114(P \leq 0.0001$; Fig. $3 \mathrm{~F})$.

\section{Corneal Sensitivity Assessed by Esthesiometry}

Postoperative recovery of corneal sensitivity is illustrated in Figure 3G. Before surgery, the average corneal sensitivity was $5.4 \pm 0.5 \mathrm{~cm}$ in the central cornea, $2.5 \pm 0.8 \mathrm{~cm}$ in the superior nasal midperiphery and $2.7 \pm 0.8 \mathrm{~cm}$ in the inferior temporal midperiphery, with no differences between the two eyes $(P \leq 1.000)$. Surgery resulted in a significant decrease in corneal sensitivity in all midperipheral zones where the cornea was cut, whether a graft was inserted or not. Sensitivity progressively returned to normal during the study period in all the midperipheral zones (preop: $2.6 \pm 0.8 \mathrm{~cm}$; day 3: $0.1 \pm$ $0.2 \mathrm{~cm}[P \leq 0.0001]$; day $114: 3.1 \pm 0.6 \mathrm{~cm}[P=0.002])$. Sensitivity in the central cornea was not affected by surgery $(P$ $=0.196)$. By the end of the study, all sensitivity values converged to a mean value of $6.0 \pm 0.0 \mathrm{~cm}$ in the central cornea and $3.1 \pm 0.6 \mathrm{~cm}$ in the midperiphery. The slight 

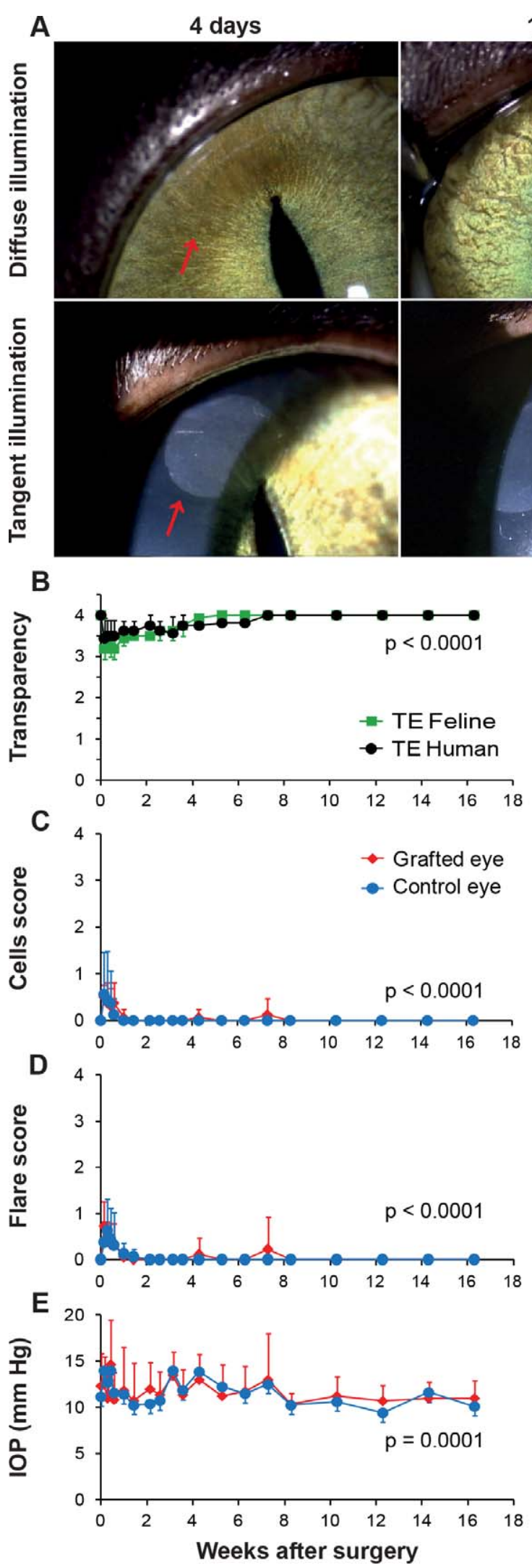

1 month
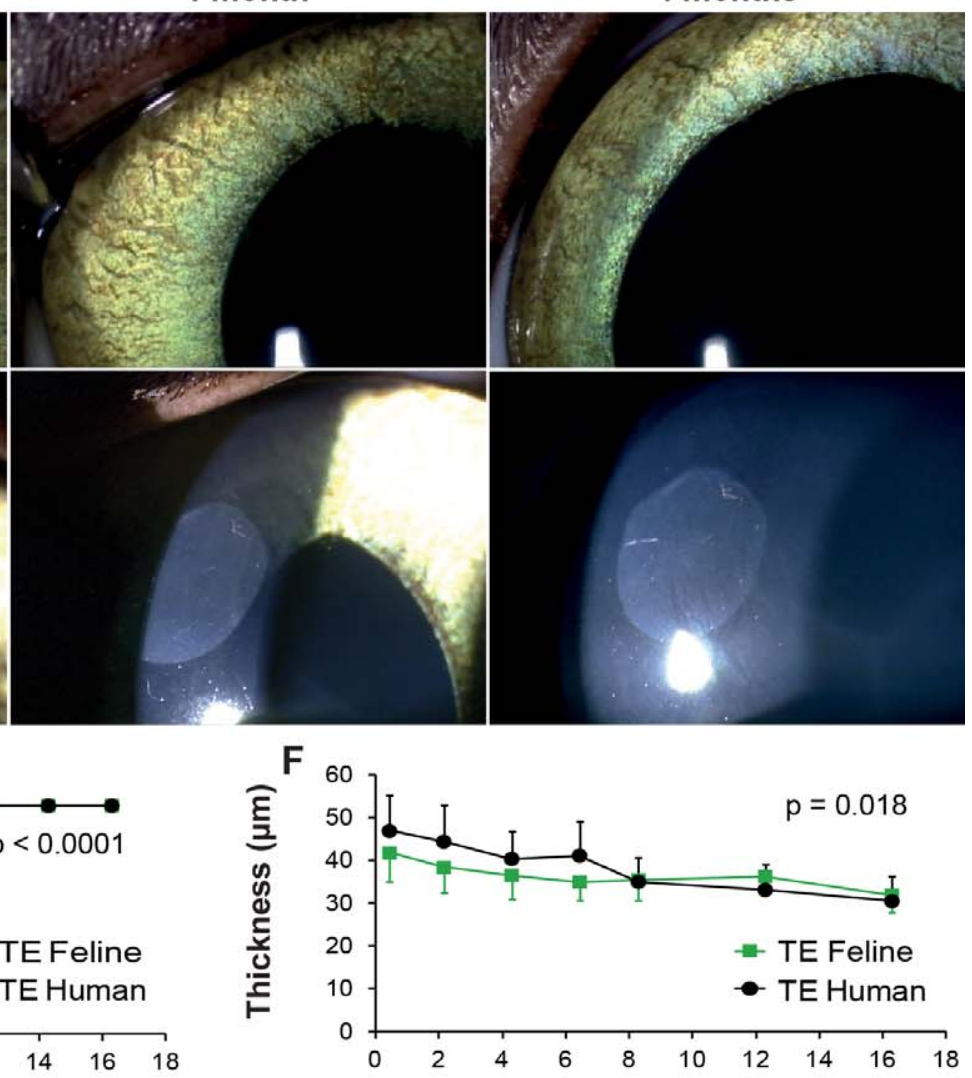

G

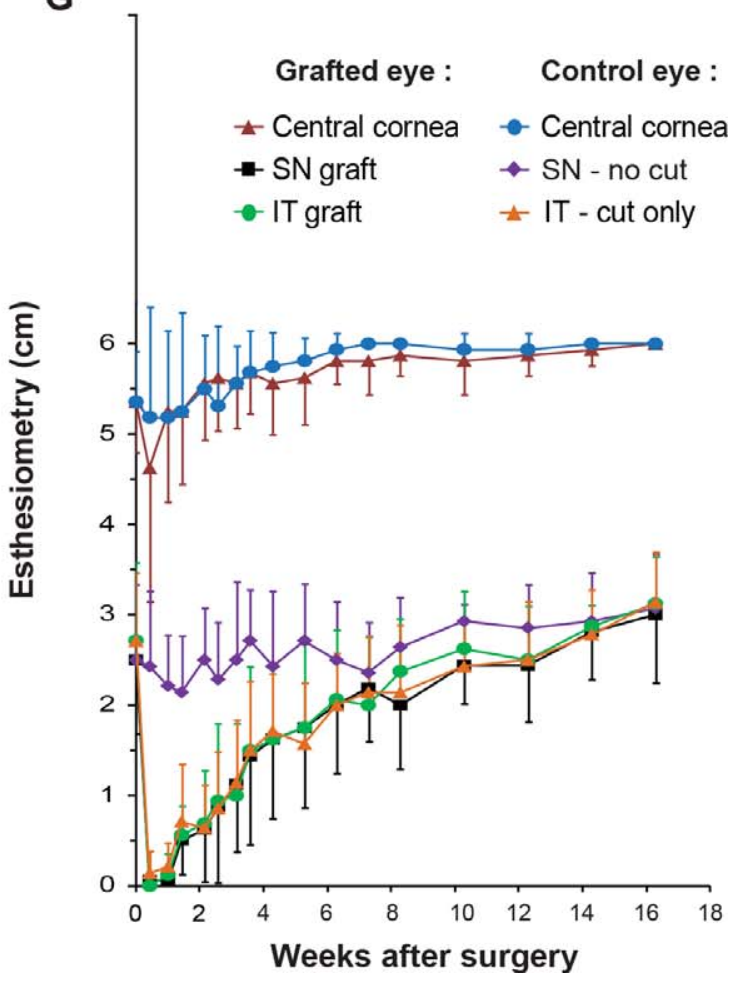

Figure 3. Clinical outcome of the TE-intrastromal grafts. (A) Representative slit-lamp photos 4 days (column 1), 1 month (column 2), and 4 months (column 3) after transplantation of a TE-stroma in the superior nasal quadrant. Regular diffuse illumination (first row) does not allow visualization of the clear graft, which can only be seen with direct tangential illumination (second row; arrow; same graft and $\times 10$ magnification for all six photographs). (B-G) Clinical evolution of grafted and control eyes. (B) Transparency score. (C) Anterior chamber cell score. (D) Anterior chamber flare score. (E) Intraocular pressure. (F) Graft thickness. (G) Esthesiometry. The parameters described in this figure were measured in all eyes at all indicated time points, with no missing data. The most representative photos are shown. 
increase above the preoperative values $(P \leq 0.0001)$ was attributed to the increased level of confidence of the animals.

\section{Histology}

Histopathology 4 months after transplantation showed smooth integration of the grafts, without surrounding scar tissue, inflammatory cellular infiltration, or vascular invasion (Fig. 2B). The multilayered epithelium and the endothelial monolayer appeared undisturbed. The stromal grafts were homogeneous, with a more compact lamellar arrangement than that seen in culture. Fibroblasts were more numerous in the grafts than in the host stroma.

\section{Nerves, Cells, and Collagen Content Assessed by Immunofluorescence}

The presence of multiple nerve filaments within these grafts 4 months after transplantation confirmed active reinnervation by the host (Fig. 2E). These new nerves tended to grow between and parallel to the stromal lamellae of the graft. Immunostaining of the xenogeneic grafts using an anti-human HLA antibody allowed to confirm that the transplanted human cells were still present in the TE-stroma 4 months after transplantation (Fig. 2J). A specific anti-human collagen IV antibody also revealed that human collagen was also present 4 months after transplantation (Fig. 2E). The expression of collagen types I and $\mathrm{V}$ in the TE-stroma was stronger in culture than after transplantation. By the end of the study, the expression of collagen I in the native and TE-stromas was similar, while that of collagen $\mathrm{V}$ was similar (Figs. 2F-I) or stronger in the grafts than in the native stroma.

\section{Corneal Innervation Assessed by Confocal Microscopy}

Confocal microscopy confirmed that all corneal layers were innervated after 4 months (Figs. $4 \mathrm{~A}-\mathrm{I}$ ). The new nerves within the grafts were different from the mature nerves of the unoperated control corneas (Figs. 4J-M). They showed higher nerve counts $\left(33 \pm 14 / \mathrm{mm}^{2}\right.$ vs. $\left.14 \pm 15 / \mathrm{mm}^{2} ; P<0.001\right)$ and greater nerve densities $\left(3708 \pm 1237 \mu \mathrm{m} / \mathrm{mm}^{2}\right.$ vs. $2024 \pm$ $\left.1374 \mu \mathrm{m} / \mathrm{mm}^{2} ; P=0.002\right)$, and they tended to be shorter (20 $\pm 7 \mu \mathrm{m}$ vs. $33 \pm 20 \mu \mathrm{m}, P=0.064)$ than the mature nerves of the unoperated controls at corresponding stromal depth. Although not statistically significant, they also appeared to be wider ( $4 \pm 2 \mu \mathrm{m}$ vs. $3 \pm 1 \mu \mathrm{m}, P=0.143$ ) and only rarely showed branching ( $6 \%$ vs. $29 \%, P=0.106$ ).

The new nerves within the grafts were identical (nerve counts, density, length, width, and branching) to the new nerves found in the recipient's stroma at the level of the incisions without a graft $(P>0.05)$. At the level of the subbasal and subepithelial plexus, no substantial differences were noted beside an increase in nerve density in the operated zones compared with the unoperated zones, both at the subbasal $(P$ $=0.022)$ and subepithelial $(P=0.016)$ levels.

\section{Transmission Electron Microscopy}

Corneal Stromal Fibroblasts. Before transplantation, abundant fibroblasts were present throughout the TE-stromas (Figs. 5A, 5B). Signs of activation included an increased density in rough endoplasmic reticulum (RER) and Golgi apparatus, numerous mitochondria, chromatin margination, and prominent nucleoli (Figs. 5C, 5D).

Four months after transplantation (Figs. 5E-H), fibroblast density in the TE-stromal grafts was still greater than in the recipient's stroma. The fibroblasts were much thinner and more elongated than in culture, their morphology being closer to that of the recipient keratocytes, which are shown in Figures 5I through 5L. While most of the features of activated fibroblasts were absent, these cells had not yet returned to a resting state.

Extracellular Matrix and Collagen Fibrils. The TEstroma in culture showed layers of wavy collagen fibrils surrounded by abundant extracellular matrix (Figs. 5A-C, 5M). Four months after transplantation, the TE-stromal grafts showed a more compact and regular architecture (Figs. 5E$\mathrm{H}, 5 \mathrm{~N}$ ), although still not as regular as that of the native stroma (Figs. 5I-L, 5O, 5P). Regularity of collagen fibrils was greater in the anterior part of the grafts compared with the posterior part of the grafts.

The mean space between collagen fibrils in the TE-stromal grafts decreased after transplantation, getting closer to that measured in nonoperated controls $(P<0.0001)$. Interfibrillar spacing was also larger in the host stroma surrounding the grafts (i.e., exposed to surgical manipulations) than in nonoperated controls $(P<0.0001)$. Mean interfibrillar distances are reported in the Table and typical examples are illustrated in Figures 5M through 5P.

The mean collagen fibril diameter in the TE-stromal grafts increased slightly after transplantation $(P<0.0001)$ and remained larger than that of the nonoperated controls $(P<$ $0.001)$. The collagen fibrils surrounding the graft were also thicker than in the nonoperated controls $(P<0.0001$; Figs. 5O, 5P; Table).

Stromal Grafts Engineered From Keratocytes of Feline Versus Human Origin. No differences were found between the TE-grafts of feline versus human origin (transparency scores, graft thickness, corneal innervation assessed by confocal microscopy, and collagen fibrils diameter and spacing as assessed by TEM; $P>0.05$ ).

\section{Discussion}

We present herein the first in vivo results on the transplantation of a corneal stroma entirely engineered in vitro from corneal stromal cells, without the addition of exogenous material or scaffold. The TE-corneal stromas in culture showed the lamellar structure characteristic of the native corneal stroma and were biocompatible to neurite outgrowth. Four months after transplantation in a feline animal model, the TEstromal grafts were clinically functional and well tolerated by the eye. They were transparent, with no adverse effect noted on the normal organization and function of the recipient's epithelial, stromal, and endothelial corneal layers, and no inflammatory reaction. There were no signs of immune rejection. Corneal sensitivity returned to preoperative level and reinnervation of the grafts was confirmed by confocal microscopy and immunofluorescence.

\section{Development of the Corneal Stroma}

In several aspects, this corneal stroma, tissue-engineered using the self-assembly approach and transplanted in the living eye, followed a structural development similar to that occurring in the embryonic eye. ${ }^{40}$ Proliferation of the stromal cells was followed by the deposition of layers of extracellular matrix, with loosely parallel collagen fibrils. Transplantation resulted in significant thinning and compaction of the TE-stroma, with a concomitant increase in tissue transparency. Fibroblasts' morphology evolved from a rounded to a flat shape more typical of mature keratocytes. The collagen fibrils became more parallel and tightly packed, resulting in an ultrastructure increasingly homogenous and similar to that of the mature 

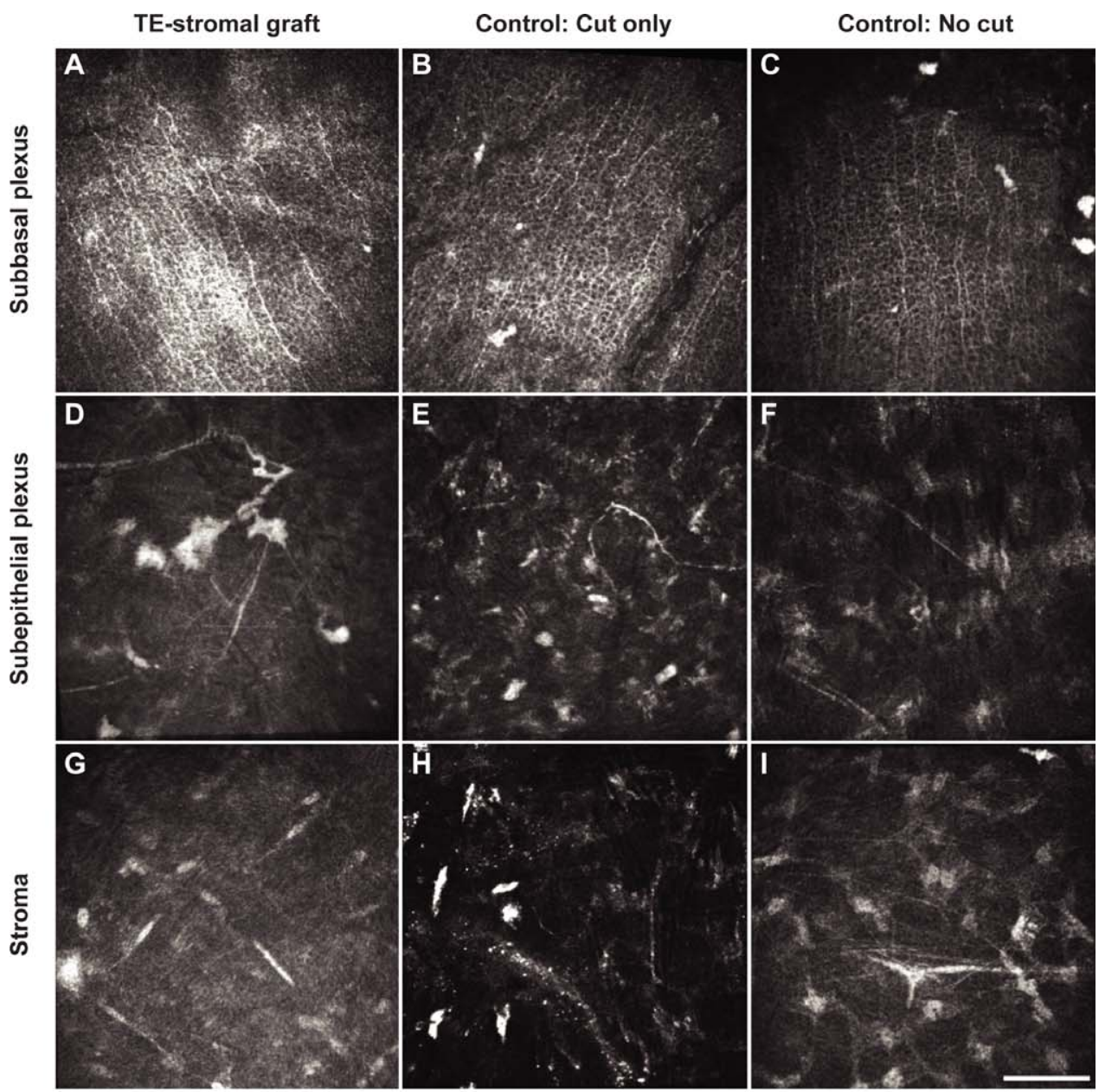

$\square$ TE-stromal graft $\quad$ Control: Cut only $\square$ Control: No cut
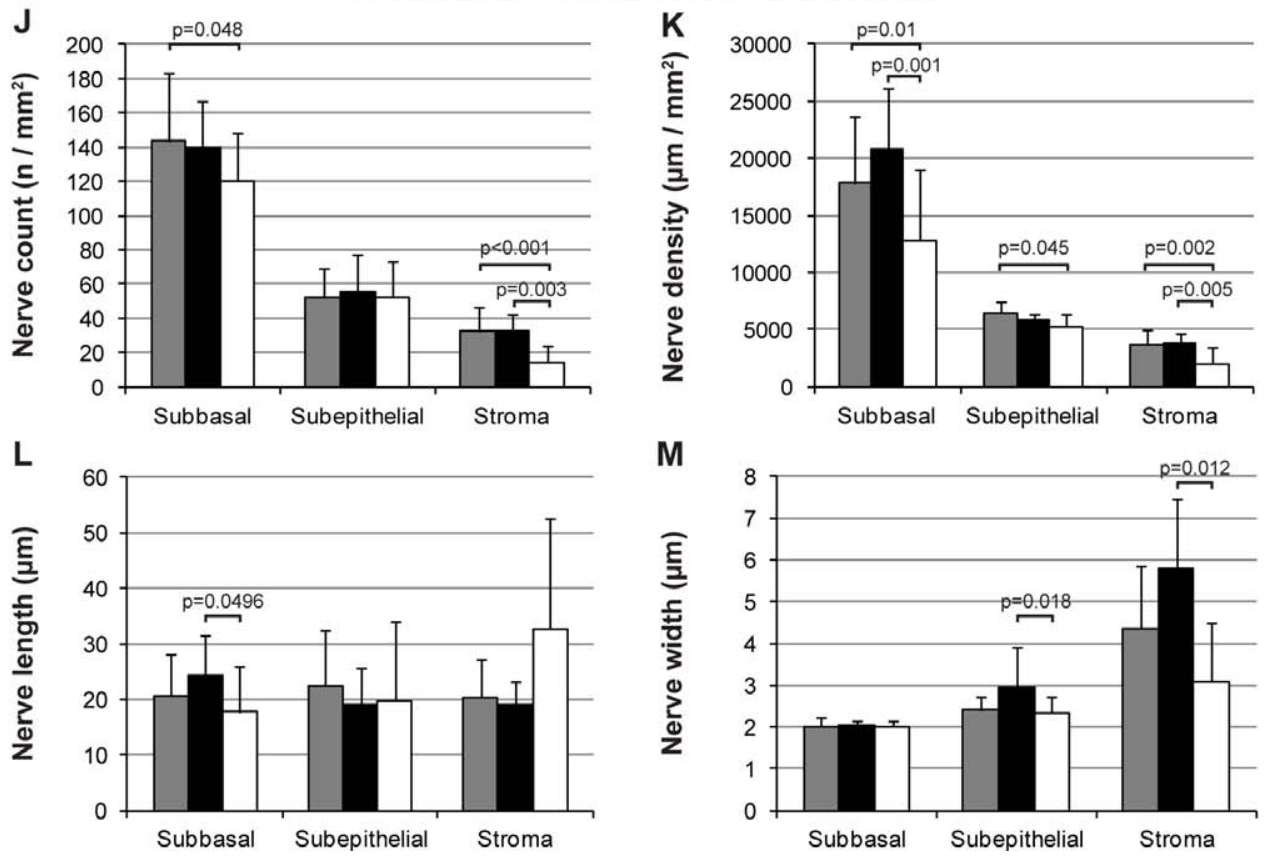

Figure 4. Corneal reinnervation 4 months after surgery. (A-I) Representative confocal images illustrating the corneal nerves within the subbasal plexus (A-C), the subepithelial plexus (D-F) and the stroma (G-I), at the level of the TE-stromal graft $(\mathbf{A}, \mathbf{D}, \mathbf{G})$, the inferior temporal quadrant of the control eye where only a surgical incision was made $(\mathbf{B}, \mathbf{E}, \mathbf{H})$, and the superior nasal quadrant of the control eye with no incision $(\mathbf{C}, \mathbf{F}, \mathbf{I})$. (J-M) Quantification of reinnervation, based on nerve count $(\mathbf{J})$, nerve density $(\mathbf{K})$, nerve length $(\mathbf{L})$ and nerve width (M) at the level of the TE-stromal graft, the superior nasal quadrant of control eye with no incision and the inferior temporal quadrant of control eye with incision. The parameters described in this figure were measured in all eyes at all indicated levels, with no missing data. Each nerve was only counted once. The most representative photos are shown. Scale bar: $50 \mu \mathrm{m}$ (same for all photographs). 

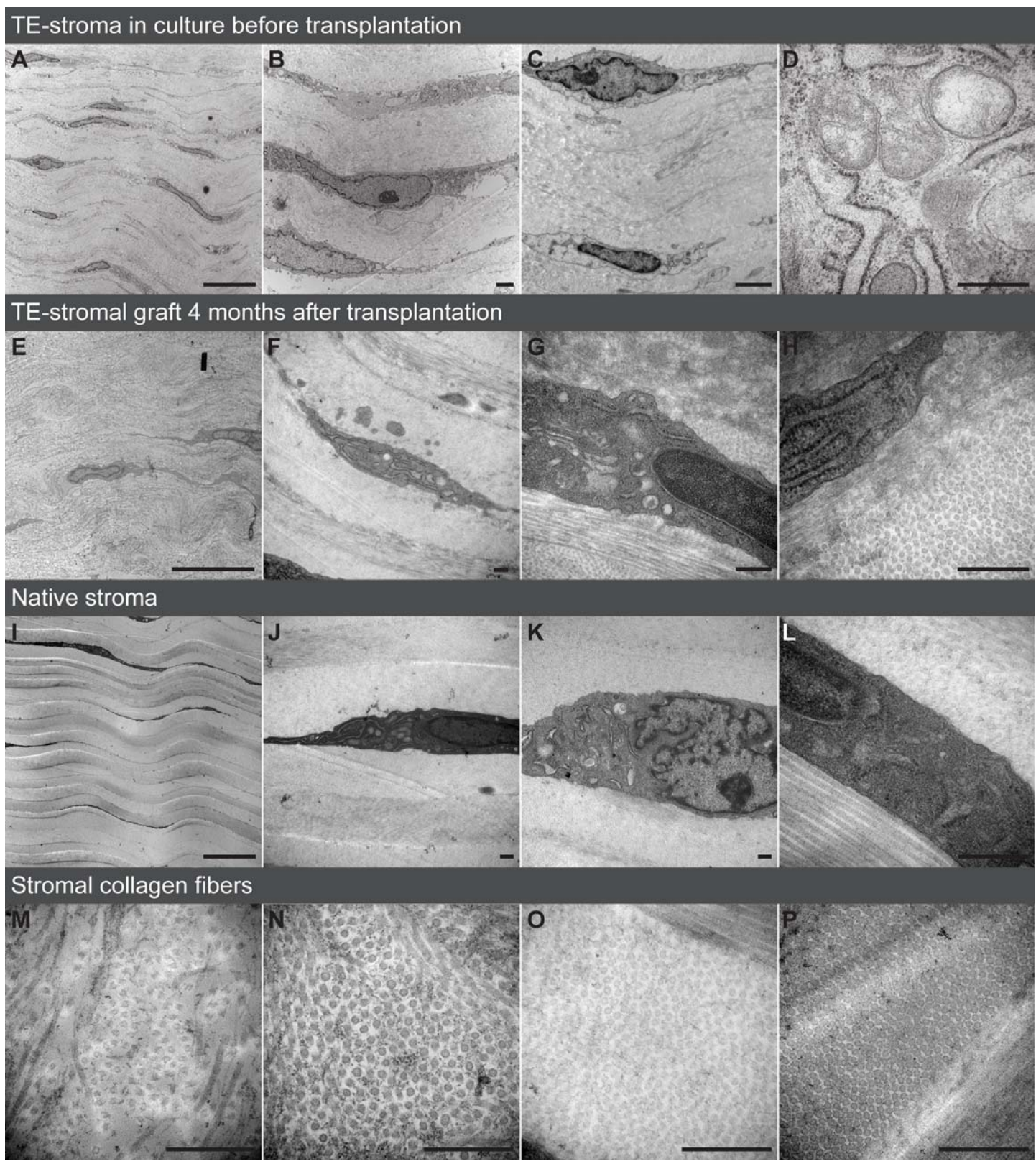

Figure 5. Transmission electron microscopy of the TE-stroma before and 4 months after surgery. (A-D) Tissue-engineered stroma in culture prior to transplantation. Thick layers of wavy stromal lamellae and numerous fibroblasts (A), most of them activated and in close proximity to each other $(\mathbf{B}, \mathbf{C})$. The prominent RER, numerous mitochondria, and vacuoles sign the high level of activity of these cells (D). (E-H) Tissue-engineered stromal graft 4 months after transplantation. The TE-stroma shows a more compact architecture than it did in culture. Fibroblast density is still superior to that of the recipient's native stroma (E). Fibroblasts are thinner and more elongated than they were in culture (G-H), showing less prominent RER, Golgi, mitochondria, and chromatin margination, but these cells were still not resting. (I-L) Recipient's native stroma in the contralateral eye (I, J) and close to the graft $(\mathbf{K}, \mathbf{L})$. The fibroblasts close to the surgical areas $(\mathbf{K}, \mathbf{L})$ are larger and more active than those in the unoperated control areas. (M-P) Transversal view of the collagen fibrils in the TE-stroma before transplantation (M), in the TE-stromal graft 4 months after transplantation (N), in the recipient's native stroma close to the graft $(\mathbf{O})$, and in the recipient's native stroma of the control eye (P). $n=9$ TE-stromas in culture and 16 ex vivo corneas. Representative photos are shown. Scale bars: $10 \mu \mathrm{m}(\mathbf{A}, \mathbf{E}, \mathbf{I}) ; 2 \mu \mathrm{m}(\mathbf{B}, \mathbf{C}) ; 500 \mathrm{~nm}(\mathbf{D}, \mathbf{F}-\mathbf{H}, \mathbf{J}-\mathbf{P})$.

native stroma. A greater regularity was observed in the anterior part of the grafts. The TE-stroma expressed collagen types I and $\mathrm{V}$, two types of fibrillar collagen normally expressed in the native cornea. The fact that the extracellular matrix secreted and assembled by the corneal fibroblasts generated a stroma that did not clinically resemble scar tissue and the absence of inflammatory reaction might in part distinguish this selfengineering process from standard wound healing.

\section{Corneal Transparency}

Transparency of a bioengineered stroma, a sine qua non condition to light transmission and vision, and maintenance of this transparency once implanted in the living eye, is challenging. Current understanding of corneal transparency favors the role of fibril spacing, which needs to be much smaller than the light wavelength and such that fluctuations in refractive index are smaller than half the light wavelength. ${ }^{41}$ 
TABLE. Collagen Fibril Diameter and Spacing

Present study

TE-stroma in culture ( $N=9$ TE-stromas; $n=40$ fibrils) ${ }^{*}$

TE-stroma at 4 months ( $N=8$ grafts; $n=40$ fibrils)

Native tissue adjacent to graft $(N=8 ; n=40)$

Normal native control $(N=8 ; n=40)$

Literature

In culture

Native stroma

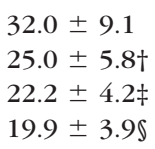

$35.5 \pm 6.0$

$39.5 \pm 4.3+$

$36.3 \pm 3.5 \neq$

$34.0 \pm 3.20$

${ }^{*} N$ indicates the number of tested tissues (TE-stromas, grafts, or controls) and $n$ indicates the number of fibrils measured in each tissue. Statistically significant differences.

$\dagger$ Between values in culture versus 4 months after transplantation $(P<0.0001)$.

¥ Between native tissue adjacent versus normal native control $(P<0.0001)$.

$\S$ Between the TE-stroma at 4 months versus normal native control (spacing: $P<0.0001$; diameter: $P<0.001$ ).

Light scattering in the cornea increases and transparency decreases when changes in the index of refraction occur locally in a zone of comparable size or larger than the wavelength, such as when the spatial arrangement of the fibrils is modified or when the fibril diameter or density increases. ${ }^{42}$ Taking advantage of the natural properties of the extracellular matrix deposited by the stromal cells and the spontaneous orientation of these fibrils ${ }^{43,44}$ allows the engineering of a transparent stroma. While encouraging progress has been made in the past decade for the production of stromal substitutes, transparency still needs to be improved in anticipation of human use. ${ }^{15,45-49}$ The delay in corneal transparency rehabilitation also has to be considered. In this study, we have gone a step further with a TE-stromal graft, allowing early and stable visualization of fine iris details during the 4-month observation period, a sign that confirms its transparency. The discrete haze only perceptible with tangential illumination allows us to believe that the TE-lamellar transplants proposed herein are very close to an optimal functional solution. Long-term studies will say if this mild residual haze resorbs with time.

\section{Stromal Fibrillar Spacing and Diameter}

The main function of native keratocytes in vivo is to maintain stromal composition by synthesizing new collagen and proteoglycans, and secreting collagenases and other enzymes to degrade old matrix. ${ }^{50}$ Proteoglycans are known to play a major role in regulating collagen fibrils size, diameter, and spatial distribution, and they are involved in the control of the swelling properties of the matrix. ${ }^{51,52}$ A variety of factors have also been shown to influence fibrillogenesis. Among them, interaction between type $\mathrm{V}$ and type I collagen would be at least partially responsible for modulating collagen fibril diameter in the corneal stroma. ${ }^{53-55}$ The composition of the self-assembled extracellular matrix has been reported elsewhere. $^{56}$

In this study, the collagen fibril diameter and spacing within our TE-stromas compared favorably with literature reports (Table). In culture, the interfibrillar spacing was closer to native stroma than what has been reported by others using different techniques ${ }^{57,58}$ and 4 months after transplantation, it was even closer to that reported for the native human stroma. ${ }^{59}$ The mean collagen fibril diameter of our TE-stromas in culture was similar to that produced by the other groups, ${ }^{57,58,60-63}$ stromal collagen fibrils produced in vitro being larger than native stromal fibrils. ${ }^{59,64-66}$ Four months after transplantation, fibrils were still somewhat larger than usually found in the native stroma.

\section{Reinnervation}

The ability of a TE-stroma to allow reinnervation is of primary importance. Corneal nerves contribute to the maintenance of a healthy ocular surface, exert a trophic influence on the corneal epithelium, and promote wound healing after eye injury. ${ }^{67} \mathrm{~A}$ dysfunctional corneal innervation induces a degenerative neurotrophic keratitis, ${ }^{68}$ resulting in chronic epithelial defects and increased risk for infection, stromal ulceration, stromal melt, and perforation. The feline model used herein was interesting because of the known similarities in innervation and sensitivity recovery between the cat and primate corneas. ${ }^{32,69}$

In this study, all stromal grafts were innervated 4 months after transplantation. As all TE-stromal grafts were devoid of any type of DRG or neural component at the time of transplantation, all neurons seen in the grafts in the living eye originated from the recipient. This provides additional evidence of their biointegration. The reinnervation patterns of the native and tissue-engineered stromal layers were similar, the new nerves being more numerous, shorter, thicker, and showing less branching than the mature nerves of the unoperated corneas.

The pattern ${ }^{70,71}$ and timing of reinnervation of the TEstromal grafts were similar to those reported for native corneal grafts in human subjects. Reinnervation of native grafts is known to start 2 to 6 months after transplantation ${ }^{38,71,72}$ and continue to progress for several decades after transplantation. ${ }^{73}$ Sensitivity recovery was also similar to that reported after corneal surgery. ${ }^{71,74}$

\section{Immunological Tolerance}

None of our grafts showed any signs of immune reaction despite the fact that:

1. Half of these TE-stromas were produced using xenogeneic human cells;

2. These grafts were inserted in the corneal periphery, very close to the limbal vasculature; and

3. Animals received only a very short course of low dose topical steroids (much less than the 1 year and more regimen routinely administered to human subjects after corneal transplantation). ${ }^{75}$

The eye benefits from immune privilege $e^{76-79}$ and corneal transplants are the least-rejected among all organ transplants. ${ }^{80}$ Furthermore, corneal rejection is typically directed against the corneal endothelium, ${ }^{80}$ while stromal rejection appears to be particularly rare. ${ }^{81}$ However, if the cellular content becomes a concern, ${ }^{82}$ the TE-stromal grafts could be decellularized prior 
to transplantation (for instance by three freeze-thaw cycles). ${ }^{83}$ Another alternative would be to engineer stromal grafts from autologous cells, which would definitely eliminate the risk of immune rejection.

\section{Translational Potential, Limitations, and Further Work}

We have demonstrated the biocompatibility and functionality of lamellar TE-stromal grafts 4 months after intrastromal transplantation in the living feline eye. Quantitative characterization of the optical and mechanical properties of these grafts and implanted corneas will be needed next. Optical assessment could involve spectral transmittance, ${ }^{84}$ absorbance, and scattering measures, while biomechanical assessment should include tensile strength measurements. ${ }^{44}$ Performance of these TE-stromal grafts will then be tested for the rehabilitation of diseased corneas. Lamellar replacement of scarred corneal layers or the filling of a pathological corneal thinning are two examples of potential clinical applications. Intracorneal filling using a biocompatible, transparent, and malleable TE-stroma is presently not a therapeutic modality clinically available. This concept could be the basis for multiple types of applications in corneal interventional surgery, including compensation for a wide range of pathological corneal thinning, such as those encountered in Terrien marginal degeneration or after infectious keratitis or trauma. Intrastromal filling in these cases may allow to avoid more invasive and higher risk interventions, such as a patch graft or a full thickness corneal transplantation. Only minimal re-expansion of the stromal volume may sometimes be necessary to rehabilitate these eyes. These TEstromas were not designed for full thickness stromal replacement and their implantation necessitates residual stromal support. Although these multilayered TE-stromas could hold a suture, no sutures need to be applied to the grafts with the intrastromal lamellar transplantation technique, thus eliminating related tissue compression, scarring, and astigmatism. Furthermore, the multilayer concept described herein may allow the thickness of the graft to adapt to individual clinical needs. There are no specific technical barriers for the transfer of these concepts to the clinic. The self-assembly approach described herein for the engineering of stromal substitutes is currently successfully used to generate other tissues (skin) for human subjects and the surgical insertion of an intrastromal graft constitutes no challenge for the corneal surgeon. Other applications of TE-stromas (that would require additional investigation) may also include their use as carrier for the in vivo transplantation of a tissue-engineered corneal endothelium. ${ }^{6-8,30}$

\section{Acknowledgments}

The authors thank Catherine Benoit-Normandin, François Berthod, Steve Breault, Sébastien Cadau, Santiago Costantino, André Deveault, José Ferreira, Karolyn Forget, Ellen Freeman, Lucie Germain, Angèle Halley, Nour Haydari, Antoine Labbé, Jean Meunier, Olivier Rochette-Drouin, Kanwarpal Singh, and François Vidal for their technical and/or intellectual support. We also thank Élodie Samson for statistical analyses.

Supported by the Académie Nationale de Médecine, Paris, France; the Canadian Institutes for Health research, Ottawa, Ontario, Canada; the Natural Sciences and Engineering Research Council of Canada, Ottawa, Ontario, Canada; the FRQS Vision Health Research Network, Québec, Canada; and the ThéCell FRQS Network, Québec, Canada; the Charles-Albert Poissant Research chair in Corneal Transplantation, University of Montreal, Québec, Canada (IB); and an unrestricted grant by Research to Prevent Blindness to the Department of Ophthalmology and Visual
Neurosciences of the School of Medicine of the University of Minnesota (JDC). The authors alone are responsible for the content and writing of the paper.

Additional information can be obtained on request.

Disclosure: M. Boulze Pankert, None; B. Goyer, None; F. Zaguia, None; M. Bareille, None; M.-C. Perron, None; X. Liu, None; J.D. Cameron, None; S. Proulx, None; I. Brunette, None

\section{References}

1. Eye Bank Association of America. 2011 Eye Banking Statistical Report. EBAA: Washington, DC; 2012.

2. World Health Organization (WHO). Prevention of blindness and visual impairment: priority eye diseases. Available at: http://www.who.int/blindness/causes/priority/en/index8. html. Accessed September 9, 2014.

3. WHO. Prevention of blindness and visual impairment: universal eye health: a global action plan 2014-2019. Available at: http://www.who.int/blindness/actionplan/en/. Accessed September 9, 2014.

4. Kobayashi T, Kan K, Nishida K, Yamato M, Okano T. Corneal regeneration by transplantation of corneal epithelial cell sheets fabricated with automated cell culture system in rabbit model. Biomaterials. 2013;34:9010-9017.

5. Xu B, Fan TJ, Zhao J, et al. Transplantation of tissue-engineered human corneal epithelium in limbal stem cell deficiency rabbit models. Int J Ophthalmol. 2012;5:424-429.

6. Levis HJ, Peh GS, Toh KP, et al. Plastic compressed collagen as a novel carrier for expanded human corneal endothelial cells for transplantation. PLoS One. 2012;7:e50993.

7. Proulx S, Bensaoula T, Nada O, et al. Transplantation of a tissue-engineered corneal endothelium reconstructed on a devitalized carrier in the feline model. Invest Ophthalmol Vis Sci. 2009;50:2686-2694.

8. Teichmann J, Valtink M, Gramm S, et al. Human corneal endothelial cell sheets for transplantation: thermo-responsive cell culture carriers to meet cell-specific requirements. Acta Biomaterialia. 2013;9:5031-5039.

9. Gomaa A, Comyn O, Liu C. Keratoprostheses in clinical practice - a review. Clin Experiment Ophthalmol. 2010;38: 211-224.

10. Zellander A, Wardlow M, Djalilian A, Zhao C, Abiade J, Cho M. Engineering copolymeric artificial cornea with salt porogen. $J$ Biomed Mater Res A. 2014;102:1799-1808.

11. Miyashita H, Shimmura S, Kobayashi H, et al. Collagenimmobilized poly(vinyl alcohol) as an artificial cornea scaffold that supports a stratified corneal epithelium. J Biomed Mater Res B Appl Biomater. 2006;76:56-63.

12. Legeais JM, Drubaix I, Briat $B$, et al. Influence of ePTFE polymer implant permeability on the rate and density of corneal extracellular matrix synthesis. J Biomed Mater Res. 1997;36:49-54.

13. Tan XW, Hartman $\mathrm{L}$, Tan KP, et al. In vivo biocompatibility of two PEG/PAA interpenetrating polymer networks as corneal inlays following deep stromal pocket implantation. J Mater Sci Mater Med. 2013;24:967-977.

14. Chen J, Li Q, Xu J, et al. Study on biocompatibility of complexes of collagen-chitosan-sodium hyaluronate and cornea. Artif Organs. 2005;29:104-113.

15. Hu X, Lui W, Cui L, Wang M, Cao Y. Tissue engineering of nearly transparent corneal stroma. Tissue Eng. 2005;11:17101717.

16. Mimura T, Amano S, Yokoo S, et al. Tissue engineering of corneal stroma with rabbit fibroblast precursors and gelatin hydrogels. Mol Vis. 2008;14:1819-1828.

17. Fagerholm P, Lagali NS, Merrett K, et al. A biosynthetic alternative to human donor tissue for inducing corneal 
regeneration: 24-month follow-up of a phase 1 clinical study. Sci Transl Med. 2010;2:46ra61.

18. Fini ME. Keratocyte and fibroblast phenotypes in the repairing cornea. Prog Retin Eye Res. 1999;18:529-551.

19. L'Heureux N, Paquet S, Labbe R, Germain L, Auger FA. A completely biological tissue-engineered human blood vessel. FASEB J. 1998;12:47-56.

20. Gauvin R, Larouche D, Marcoux H, Guignard R, Auger FA, Germain L. Minimal contraction for tissue-engineered skin substitutes when matured at the air-liquid interface. $J$ Tissue Eng Regen Med. 2013;7:452-460.

21. Boa O, Cloutier CB, Genest H, et al. Prospective study on the treatment of lower-extremity chronic venous and mixed ulcers using tissue-engineered skin substitute made by the self-assembly approach. Adv Skin Wound Care. 2013;26:400409.

22. Gauvin R, Ahsan T, Larouche D, et al. A novel single-step selfassembly approach for the fabrication of tissue-engineered vascular constructs. Tissue Eng Part A. 2010;16:1737-1747.

23. Vermette M, Trottier V, Menard V, Saint-Pierre L, Roy A, Fradette J. Production of a new tissue-engineered adipose substitute from human adipose-derived stromal cells. Biomaterials. 2007;28:2850-2860.

24. Germain L, Carrier P, Auger FA, Salesse C, Guerin SL. Can we produce a human corneal equivalent by tissue engineering? Prog Retin Eye Res. 2000;19:497-527.

25. Germain LGC, Carrier P, Guérin SL, Salesse C, Auger FA. Tissue engineering of cornea. In: Wnek GEBG, ed. Encyclopedia of Biomaterials and Biomedical Engineering. New York: Marcel Dekker; 2004:1534-1544.

26. Proulx S, d'Arc Uwamaliya J, Carrier P, et al. Reconstruction of a human cornea by the self-assembly approach of tissue engineering using the three native cell types. Mol Vis. 2010; 16:2192-2201.

27. Durham HD, Roy J, Dong L, Figlewicz DA. Aggregation of mutant $\mathrm{Cu} / \mathrm{Zn}$ superoxide dismutase proteins in a culture model of ALS. J Neuropathol Exp Neurol. 1997;56:523-530.

28. Blais $M$, Grenier M, Berthod $F$. Improvement of nerve regeneration in tissue-engineered skin enriched with Schwann cells. J Invest Dermatol. 2009;129:2895-2900.

29. Brunette I, Rosolen SG, Carrier M, et al. Comparison of the pig and feline models for full thickness corneal transplantation. Vet Ophthalmol. 2011;14:365-377.

30. Haydari MN, Perron MC, Laprise S, et al. A short-term in vivo experimental model for Fuchs endothelial corneal dystrophy. Invest Ophthalmol Vis Sci. 2012;53:6343-6354.

31. Jabs DA, Nussenblatt RB, Rosenbaum JT. Standardization of uveitis nomenclature working. standardization of uveitis nomenclature for reporting clinical data. Results of the first international workshop. Am J Ophthalmol. 2005;140:509516.

32. Chang-Ling T, Vannas A, Holden BA, O'Leary DJ. Incision depth affects the recovery of corneal sensitivity and neural regeneration in the cat. Invest Ophthalmol Vis Sci. 1990;31: 1533-1541.

33. Labbe A, Alalwani H, Van Went C, Brasnu E, Georgescu D, Baudouin $C$. The relationship between subbasal nerve morphology and corneal sensation in ocular surface disease. Invest Ophthalmol Vis Sci. 2012;53:4926-4931.

34. Abramoff MD, Magalhães PJ; Ram SJ. Image processing with ImageJ. Biophotonics Int. 2004;11:36-42.

35. Freegard TJ. The physical basis of transparency of the normal cornea. Eye. 1997;11(pt 4):465-471.

36. Meijering E, Jacob M, Sarria JC, Steiner P, Hirling H, Unser M. Design and validation of a tool for neurite tracing and analysis in fluorescence microscopy images. Cytometry A. 2004;58: 167-176.
37. Oliveira-Soto L, Efron N. Morphology of corneal nerves using confocal microscopy. Cornea. 2001;20:374-384.

38. Calvillo MP, McLaren JW, Hodge DO, Bourne WM. Corneal reinnervation after LASIK: prospective 3-year longitudinal study. Invest Ophthalmol Vis Sci. 2004;45:3991-3996.

39. Lagali N, Griffith M, Fagerholm P, Merrett K, Huynh M, Munger $R$. Innervation of tissue-engineered recombinant human collagen-based corneal substitutes: a comparative in vivo confocal microscopy study. Invest Ophthalmol Vis Sci. 2008; 49:3895-3902.

40. Quantock AJ, Young RD. Development of the corneal stroma, and the collagen-proteoglycan associations that help define its structure and function. Dev Dyn. 2008;237:2607-2621.

41. Benedek GB. Theory of transparency of the eye. Appl Opt. 1971;10:459-473.

42. Meek KM, Leonard DW, Connon CJ, Dennis S, Khan S. Transparency, swelling and scarring in the corneal stroma. Eye. 2003;17:927-936.

43. Doane KJ, Birk DE. Fibroblasts retain their tissue phenotype when grown in three-dimensional collagen gels. Exp Cell Res. 1991; 195:432-442.

44. Guillemette MD, Cui B, Roy E, et al. Surface topography induces 3D self-orientation of cells and extracellular matrix resulting in improved tissue function. Integr Biol (Camb). 2009; 1:196-204.

45. Tanaka Y, Shi D, Kubota A, et al. Irreversible optical clearing of rabbit dermis for autogenic corneal stroma transplantation. Biomaterials. 2011;32:6764-6772.

46. Zhang YQ, Zhang WJ, Liu W, et al. Tissue engineering of corneal stromal layer with dermal fibroblasts: phenotypic and functional switch of differentiated cells in cornea. Tissue Eng Part A. 2008;14:295-303.

47. Zhang C, Nie X, Hu D, et al. Survival and integration of tissueengineered corneal stroma in a model of corneal ulcer. Cell Tissue Res. 2007;329:249-257.

48. Yoeruek E, Bayyoud T, Maurus C, et al. Reconstruction of corneal stroma with decellularized porcine xenografts in a rabbit model. Acta Ophthalmol. 2012;90:e206-e210.

49. Takiyama N, Mizuno T, Iwai R, Uechi M, Nakayama Y. In-body tissue-engineered collagenous connective tissue membranes (BIOSHEETs) for potential corneal stromal substitution [published online ahead of print December 10, 2013].J Tissue Eng Regen Med. doi:10.1002/term.1859.

50. Brown D, Chwa M, Escobar M, Kenney MC. Characterization of the major matrix degrading metalloproteinase of human corneal stroma. Evidence for an enzyme/inhibitor complex. Exp Eye Res. 1991;52:5-16.

51. Chakravarti S, Magnuson T, Lass JH, Jepsen KJ, LaMantia C, Carroll H. Lumican regulates collagen fibril assembly: skin fragility and corneal opacity in the absence of lumican. $J$ Cell Biol. 1998;141:1277-1286.

52. Rada JA, Cornuet PK, Hassell JR. Regulation of corneal collagen fibrillogenesis in vitro by corneal proteoglycan (lumican and decorin) core proteins. Exp Eye Res. 1993;56: 635-648.

53. Birk DE. Type $\mathrm{V}$ collagen: heterotypic type $\mathrm{I} / \mathrm{V}$ collagen interactions in the regulation of fibril assembly. Micron. 2001; 32:223-237.

54. Birk DE, Fitch JM, Babiarz JP, Doane KJ, Linsenmayer TF. Collagen fibrillogenesis in vitro: interaction of types I and V collagen regulates fibril diameter. J Cell Sci. 1990;95(pt 4): 649-657.

55. Hassell JR, Birk DE. The molecular basis of corneal transparency. Exp Eye Res. 2010;91:326-335.

56. Lake J, Zaniolo K, Gaudreault M, et al. Expression of the alpha5 integrin gene in corneal epithelial cells cultured on tissue- 
engineered human extracellular matrices. Biomaterials. 2013; 34:6367-6376

57. Wu J, Du Y, Watkins SC, Funderburgh JL, Wagner WR. The engineering of organized human corneal tissue through the spatial guidance of corneal stromal stem cells. Biomaterials. 2012;33:1343-1352.

58. Builles N, Justin V, Andre V, Burillon C, Damour O. Reconstructed corneas: effect of three-dimensional culture, epithelium, and tetracycline hydrochloride on newly synthesized extracellular matrix. Cornea. 2007;26:1239-1248.

59. Muller LJ, Pels E, Schurmans LR, Vrensen GF. A new threedimensional model of the organization of proteoglycans and collagen fibrils in the human corneal stroma. Exp Eye Res. 2004;78:493-501.

60. Builles N, Janin-Manificat $H$, Malbouyres $M$, et al. Use of magnetically oriented orthogonal collagen scaffolds for hemicorneal reconstruction and regeneration. Biomaterials. 2010; 31:8313-8322.

61. Guo X, Hutcheon AE, Melotti SA, Zieske JD, Trinkaus-Randall V, Ruberti JW. Morphologic characterization of organized extracellular matrix deposition by ascorbic acid-stimulated human corneal fibroblasts. Invest Ophthalmol Vis Sci. 2007; 48:4050-4060.

62. Karamichos D, Hutcheon AE, Zieske JD. Transforming growth factor-beta3 regulates assembly of a non-fibrotic matrix in a 3D corneal model. J Tissue Eng Regen Med. 2011;5:e228-e238.

63. Wu J, Du Y, Mann MM, Yang E, Funderburgh JL, Wagner WR. Bioengineering organized, multilamellar human corneal stromal tissue by growth factor supplementation on highly aligned synthetic substrates. Tissue Eng Part A. 2013;19:2063-2075.

64. Hirsch M, Prenant G, Renard G. Three-dimensional supramolecular organization of the extracellular matrix in human and rabbit corneal stroma, as revealed by ultrarapid-freezing and deep-etching methods. Exp Eye Res. 2001;72:123-135.

65. Meek KM, Fullwood NJ. Corneal and scleral collagens-a microscopist's perspective. Micron. 2001;32:261-272.

66. Miyagawa A, Kobayashi M, Fujita Y, et al. Surface ultrastructure of collagen fibrils and their association with proteoglycans in human cornea and sclera by atomic force microscopy and energy-filtering transmission electron microscopy. Cornea. 2001;20:651-656.

67. Muller LJ, Marfurt CF, Kruse F, Tervo TM. Corneal nerves: structure, contents and function. Exp Eye Res. 2003;76:521542.

68. Lambiase A, Rama P, Aloe L, Bonini S. Management of neurotrophic keratopathy. Curr Opin Ophthalmol. 1999;10: 270-276.

69. Chan-Ling T. Sensitivity and neural organization of the cat cornea. Invest Ophthalmol Vis Sci. 1989;30:1075-1082.
70. Al-Aqaba MA, Otri AM, Fares U, Miri A, Dua HS. Organization of the regenerated nerves in human corneal grafts. $A m J$ Ophthalmol. 2012;153:29-37.e24.

71. Darwish T, Brahma A, Efron N, O'Donnell C. Subbasal nerve regeneration after penetrating keratoplasty. Cornea. 2007;26: 935-940.

72. Richter A, Slowik C, Somodi S, Vick HP, Guthoff R. Corneal reinnervation following penetrating keratoplasty-correlation of esthesiometry and confocal microscopy. Ger J Ophthalmol. 1996;5:513-517.

73. Patel SV, Erie JC, McLaren JW, Bourne WM. Keratocyte density and recovery of subbasal nerves after penetrating keratoplasty and in late endothelial failure. Arch Ophthalmol. 2007;125: 1693-1698.

74. Darwish T, Brahma A, O'Donnell C, Efron N. Subbasal nerve fiber regeneration after LASIK and LASEK assessed by noncontact esthesiometry and in vivo confocal microscopy: prospective study. J Cataract Refract Surg. 2007;33:15151521.

75. Price FW Jr, Price DA, Ngakeng V, Price MO. Survey of steroid usage patterns during and after low-risk penetrating keratoplasty. Cornea. 2009;28:865-870.

76. Streilein JW. Ocular immune privilege: therapeutic opportunities from an experiment of nature. Nat Rev Immunol. 2003;3: 879-889.

77. Niederkorn JY. See no evil, hear no evil, do no evil: the lessons of immune privilege. Nat Immunol. 2006;7:354-359.

78. Niederkorn JY. Cornea: window to ocular immunology. Curr Immunol Rev. 2011;7:328-335.

79. Niederkorn JY, Larkin DF. Immune privilege of corneal allografts. Ocular Immunol Inflamm. 2010;18:162-171.

80. Chong EM, Dana MR. Graft failure IV. Immunologic mechanisms of corneal transplant rejection. Int Ophthalmol. 2008; 28:209-222.

81. Noble BA, Agrawal A, Collins C, Saldana M, Brogden PR, Zuberbuhler B. Deep anterior lamellar keratoplasty (DALK): visual outcome and complications for a heterogeneous group of corneal pathologies. Cornea. 2007;26:59-64.

82. Hori J, Joyce NC, Streilein JW. Immune privilege and immunogenicity reside among different layers of the mouse cornea. 2000. Ocul Immunol Inflamm. 2007;15:225-239.

83. Proulx S, Audet C, Uwamaliya J, et al. Tissue engineering of feline corneal endothelium using a devitalized human cornea as carrier. Tissue Eng Part A. 2009;15:1709-1718.

84. DiVito MD, Rudisill SG, Stein A, Patel SV, McLaren JW, Hubel A. Silica hybrid for corneal replacement: optical, biomechanical, and ex vivo biocompatibility studies. Invest Ophthalmol Vis Sci. 2012;53:8192-8199. 